\title{
Impact of awareness of the Japanese Food Guide Spinning Top on eating behaviour
}

\author{
Kanae Takaizumi ${ }^{1,2, *}$, Kazuhiro Harada ${ }^{3}$, Ai Shibata ${ }^{4}$ and Yoshio Nakamura ${ }^{4}$ \\ ${ }^{1}$ Graduate School of Sport Sciences, Waseda University, Nakamura Yoshio lob, 2-579-15, Mikajima, \\ Tokorozawa, Saitama 359-1 192, Japan: ${ }^{2}$ Morioka Junior College, Department of Life Science, Iwate Prefectural \\ University, Iwate, Japan: ${ }^{3}$ Research Fellow of the Japan Society for the Promotion of Science, Chiyoda, Japan: \\ ${ }^{4}$ Faculty of Sport Sciences, Waseda University, Saitama, Japan
}

Submitted 15 October 2010: Accepted 22 June 2011: First published online 23 August 2011

\begin{abstract}
Objective: To investigate whether awareness of the Japanese Food Guide (JFG) can promote changes in eating behaviour.

Design: A longitudinal study was conducted in 2007 and 2009 by means of an Internet-based survey. Awareness status of the JFG and a sixteen-item scale for calculating eating behaviour scores were obtained.

Setting: Japan.

Subjects: In total, 787 Japanese adults (20-59 years) who registered with an Internet research service organization were included in the study. The respondents were divided into three groups. The respondents who were aware of the JFG in 2007 were categorized into Group 1. Those who were not aware of the JFG in 2007 were categorized into either Group 2 or Group 3. Group 2 became aware of the JFG by 2009, and Group 3 was not aware of the JFG in 2009.

Results: In Group 2, the eating behaviour score increased significantly by 0.8 points from 4.7 in 2007 to 5.5 in $2009(P=0.004)$. The eating behaviour score of Group $1(6.5$ points in $2007 ; 6.3$ points in 2009) and Group $3(3.8$ points in 2007; $4 \cdot 1$ points in 2009) did not change significantly from 2007 to 2009.

Conclusions: Awareness of the JFG promoted eating behaviour change in the Japanese population. The results indicate that awareness of nutrition information from sources such as the JFG would promote healthy eating.
\end{abstract}

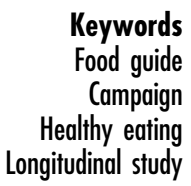

Dietary guidelines have been developed by many countries to help promote healthy dietary habits and to prevent obesity. In 2005, the Japanese Government developed the Japanese Food Guide Spinning Top (JFG) to help Japanese people implement dietary guidelines to promote healthy eating ${ }^{(1,2)}$. The US Government developed the Food Guide Pyramid in 1992 and modified it as MyPyramid in 2005. The Australian Government developed the Australian Guide to Healthy Eating, with a message 'Enjoy a variety of food every day'. The JFG is unique in that it is expressed in quantities of the 'dish' rather than in the 'food' format to estimate the quantity of food consumed in a daily diet and that it uses the analogy of the shape of a spinning top, which incorporates an aspect of Japanese culture ${ }^{(2)}$. The JFG indicates that a balanced diet and physical activity are important to keep the top spinning (keep healthy). In addition, the JFG not only describes the optimal food intake for Japanese people but also provides nutritional messages that aim to enhance the awareness of healthy eating ${ }^{(1)}$.

The Ministry of Agriculture, Forestry and Fisheries of Japan has been actively and continuously conducting nationwide campaigns via mass media to promote awareness of the JFG among the Japanese population since 2006. The campaign consisted of advertisements showing the image of a famous Japanese actress on television, buses and trains. There were also events aimed at raising awareness among students, the younger generations, middle-aged men, nurturers, the elderly and people living alone. Dissemination of the JFG was promoted by organizations such as supermarkets, convenience stores, restaurants, schools, kindergartens, transportation facilities and public facilities ${ }^{(3)}$. Communication campaigns have been shown to be one of the most effective strategies for changing eating behaviours at the population level ${ }^{(4)}$. Additionally, communication campaigns are managed in a stepwise process by first raising awareness of the campaign message, which consequently leads to a change in knowledge, attitudes and behaviour ${ }^{(5,6)}$. Thus, disseminating the JFG with the communication campaign and increasing awareness of the JFG may consequently promote healthy eating behaviour.

Awareness of the JFG was found to indirectly influence eating behaviour via eating knowledge, an essential mediator of the association between awareness of the JFG 


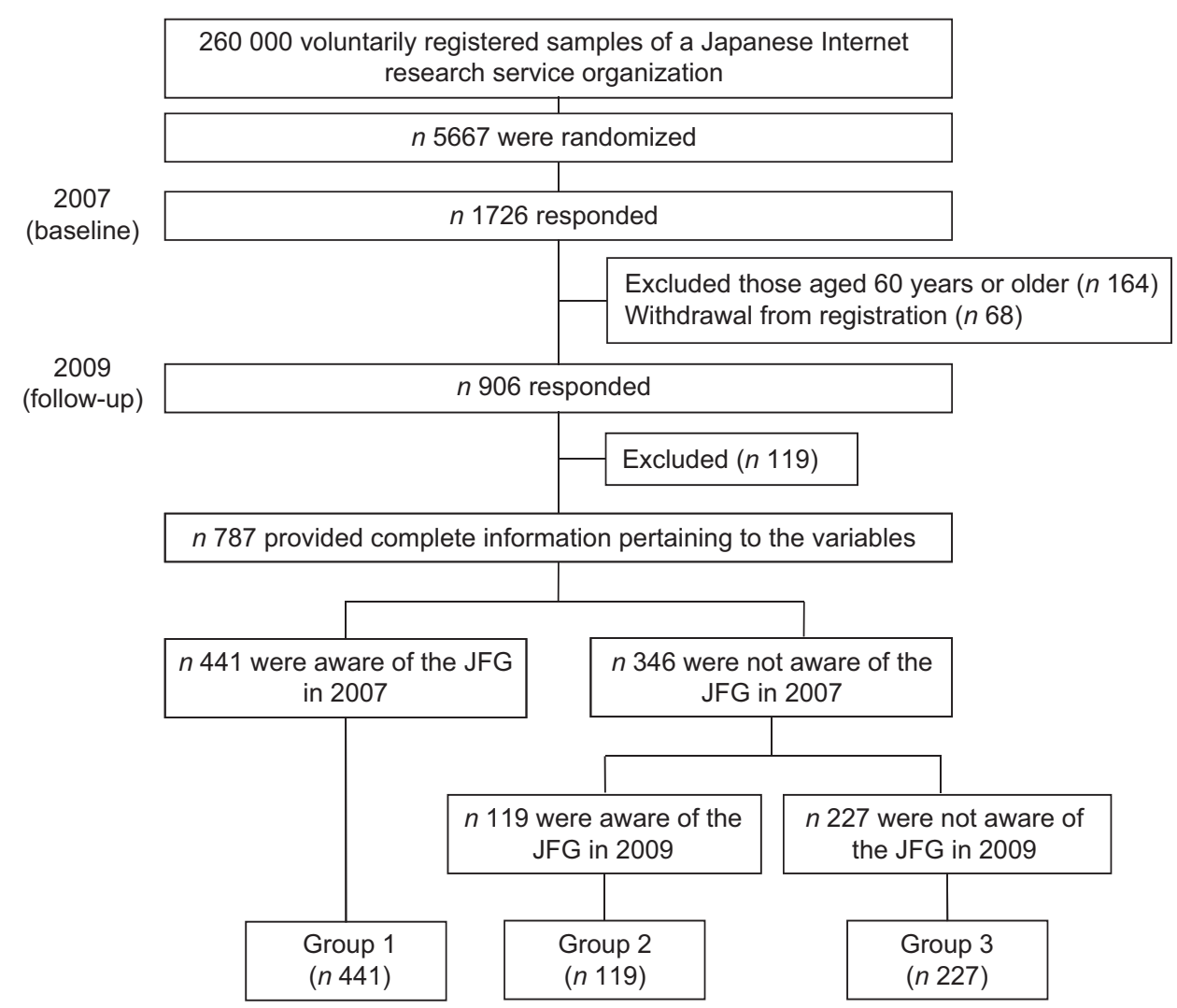

Fig. 1 Flow diagram of participants through the survey

and eating behaviour, in a cross-sectional survey ${ }^{(7)}$. However, it is unclear whether there is a causal relationship between awareness of the JFG and eating behaviour among Japanese people. Although effects of communication campaigns on eating behaviour have been reported in several previous studies, almost all were conducted in Western countries ${ }^{(8-10)}$. For example, the 'Face the Fats' campaign reported that increased awareness of trans fats was directly associated with improved behaviour regarding grocery shopping among Americans ${ }^{(9)}$. Few studies have examined the effects of nutritional campaigns on eating behaviour in Eastern countries including Japan ${ }^{(11)}$. Additionally, most of these studies had cross-sectional designs. Compared with a cross-sectional research design, to evaluate the effects of a campaign, longitudinal research designs can more appropriately evaluate the process of behavioural change ${ }^{(12)}$. Therefore, examining the effects of awareness of the JFG on eating behaviour with a longitudinal design is necessary to demonstrate the importance of awareness for promoting healthy eating in the Japanese population.

Incidentally, the broad target population for dissemination of the JFG includes those with obesity, unhealthy eating or little interest in improving their diet. In fact, awareness of the JFG increased from $26.0 \%$ in 2006 to $40.7 \%$ in 2007 as a result of the campaign conducted by the Japanese Government ${ }^{(3)}$. However, it is not known what sociodemographic characteristics the JFG reached. According to the previous study, males, older people and those with high socio-economic status were less likely to be aware of the nutritional campaign ${ }^{(8)}$. To evaluate the efficacy of the JFG dissemination, it is necessary to examine the sociodemographic characteristics associated with those who are aware of the JFG.

The purpose of the present study was to explore whether awareness of the JFG influenced changes in eating behaviour among Japanese adults by using a longitudinal study design. In addition, the present study examined the sociodemographic characteristics associated with awareness of the JFG.

\section{Methods}

\section{Study design and participants}

The participants in the present study included Japanese adults who responded to an Internet-based longitudinal survey, which was conducted through a Japanese Internet research service organization. The organization owns approximately 260000 voluntary registered samples, had access to samples of detailed sociodemographic attributes, and was able to target specific attributes according to each survey requirement. A baseline survey was conducted in November 2007 and a follow-up survey was conducted in November 2009 (Fig. 1). 
The baseline survey requirement in the present study was to collect data from approximately 1700 male and female adults aged 20-79 years, with an equivalent number of males and females in each age bracket. A total of 5667 potential respondents were randomly and blindly selected from approximately 260000 registrants aged 20-79 years in the database. They were invited to participate in the Internet-based survey via email. The invitation email contained a URL directing them to a protected area of the website, from where the questionnaire could be accessed. They could log in using their own log-in ID and password. As an incentive for participation, the Internet research organization offered reward points valued at 80 yen. A total of 1726 males and females responded (response rate: $31 \%$ ). The follow-up survey was conducted for all responders of the baseline survey excluding those who withdrew from registration $(n 68)$ and those aged 60 years or older ( $n$ 164); the latter were considered a minority of the registered sample and a heterogeneous group in the general Internet user population because the total Internet penetration rate in Japan in 2007 was $69.0 \%$, while that among people aged 60 years and over was only $36 \cdot 0 \%{ }^{(13)}$. The data collecting procedure of the follow-up survey was the same as that of the baseline survey. Reward points of the follow-up survey were valued at 70 yen. The participants of the present study consisted of the 906 male and female respondents in both surveys. The present study did not obtain written consent of the respondent. Respondents who completed the questionnaire and clicked on the 'send' button at the end of the online information consent were considered to have agreed to participate in both surveys. The study protocol was reviewed and approved by the ethics committee of Waseda University.

Data were analysed for 787 individuals who provided complete information pertaining to the current study variables. The respondents were divided into three groups. Respondents who were aware of the JFG in 2007 were categorized in Group 1 ( $n$ 441). On the other hand, the respondents who were not aware of the JFG in 2007 were classified as either Group 2 ( $n$ 119) or Group 3 ( $n$ 227). Respondents in Group 2 were those who become aware of the JFG by 2009, while respondents in Group 3 were not aware of the JFG even in 2009 (Fig. 1).

\section{Measurements}

Awareness of the Japanese Food Guide Spinning Top The primary independent variable in the present study was exposure to the JFG, as measured by individual awareness of the JFG. Participants were asked 'Do you know the JFG?' Response choices were set as a 4-item Likert scale. For awareness, the choices of 'I know the contents' and 'I have heard of it, but I do not know the contents' were categorized as 'awareness', whereas 'I have not heard of it' and 'The first time I have heard of it is via this survey' were included in another category of 'no awareness'. Awareness was scored as 1, and no awareness was scored as 0 for analysis.

\section{Eating behaviour}

The dependent variable was eating behaviour, which was assessed by sixteen questions (using yes/no response; 1 point $v$. 0 points) as shown in the Appendix ${ }^{(7)}$. The total score ranged from 0 to 16 for eating behaviour. The questions included items concerning healthy eating behaviour recommended by Health Japan $21^{(14)}$ and the $\mathrm{JFG}^{(1)}$ and used in the Japanese National Health and Nutrition Examination Survey ${ }^{(15)}$. A higher score indicated engaging in a lot of recommended eating behaviours. Thus, a higher score was considered to indicate healthier eating behaviour and a lower score indicated less healthy eating behaviour.

\section{Demographic variables}

Demographic variables included gender, age, marital status, educational status, employment status, household income, BMI and waist circumference (WC). Age groups were classified as $20-29,30-39,40-49$ and $50-59$ years. Marital status was categorized as currently married or currently unmarried. Educational status was classified as less than high-school graduate, junior college graduate or equivalent, or college graduate or higher. Employment status was categorized as employed or not employed. Annual household income was classified into three categories ranging from less than 5000000 yen to 10000000 yen or more. BMI was calculated from self-reported height and weight. Self-reported height and weight have been demonstrated to be strongly correlated with the objective measurement ${ }^{(16)}$. WC was determined by self-report. Participants were asked: 'Does your waist circumference meet the criterion (males $\geq 85 \mathrm{~cm}$, females $\geq 90 \mathrm{~cm}$ ) ${ }^{(17)}$. Participants were asked to choose one of the following answers: 'yes', 'no' or 'I do not know'. These responses were dichotomized as 'yes' (abdominal obesity) and 'no' (no abdominal obesity). 'Do not know' responses were excluded from the analysis.

\section{Statistical analyses}

All statistical analyses were performed using the SPSS statistical software package version $16 \cdot 0 \mathrm{j}$ (SPSS Inc., Chicago, IL, USA). Statistical significance was set at $P<0 \cdot 05$.

Logistic regression analysis was used to analyse the relationship between awareness and demographic variables. Changes in awareness (2007-2009) were analysed using the McNemar test. Changes in eating behaviour score (2007-2009) were analysed with the Wilcoxon test for each awareness group stratified by gender. 


\section{Results}

\section{Basic characteristics of respondents}

Table 1 presents the distribution of gender, age, marital status, educational status, employment status, annual household income, BMI and WC among the respondents. The respondents were 787 Japanese adults ( 410 males and 377 females), with a mean age of 39.8 (SD 9.7) years. Overall, $19 \%$ of the respondents had a BMI greater than $25 \cdot 0 \mathrm{~kg} / \mathrm{m}^{2}$, and $22 \%$ of the respondents were classified as having abdominal obesity based on the WC criterion ${ }^{(17)}$. Sixty-four per cent of respondents were married. Twentyseven per cent of the respondents had less than a highschool graduate level of education, whereas $48 \%$ graduated from college or graduate school. Sixty-three per cent of respondents were employed, and $40 \%$ of the respondents had an annual household income of less than 5000000 yen. Fourteen per cent earned more than 10000000 yen per annum. Responders were more likely to have higher educational status than the general Japanese population ${ }^{(15,18-20)}$.

\section{Awareness of the Japanese Food Guide Spinning Top}

Awareness of the JFG was 56.0\% in 2007 and $61.8 \%$ in 2009 ( $P=0 \cdot 001$; Table 3). In 2009, among the 346 respondents who were not aware of the JFG in $2007,34.4 \%$ of respondents became aware of the JFG and $65 \cdot 6 \%$ of respondents were not aware of the JFG. Overall, $28 \cdot 8 \%$ of respondents remained unaware of the JFG in 2009.

\section{Association between awareness of the Japanese Food Guide Spinning Top and sociodemographic characteristics}

In the unadjusted analysis, male gender $(\mathrm{OR}=0 \cdot 26,95 \%$ CI $0 \cdot 17,0 \cdot 36)$, abdominal obesity (OR $=0.44,95 \%$ CI $0 \cdot 31,0 \cdot 62)$ and employed $(\mathrm{OR}=0.54,95 \% \mathrm{CI} 0 \cdot 40,0 \cdot 72)$ were negatively associated with awareness of the JFG. Married $(\mathrm{OR}=1.53,95 \% \mathrm{CI} 1 \cdot 14,2 \cdot 06)$ and annual household income of 5000 000-9999999 yen (OR = 1.53, $95 \%$ CI $1 \cdot 13,2 \cdot 07$ ) were positively associated with awareness of the JFG. After adjusting for all variables, male gender $(\mathrm{OR}=0 \cdot 26,95 \%$ CI $0 \cdot 17,0 \cdot 39)$ and abdominal obesity (OR $=0 \cdot 65,95 \%$ CI $0 \cdot 42,1 \cdot 00)$ were negatively associated with awareness of the JFG . Annual household income of 5000 000-9999999 yen (OR = 1•48, $95 \%$ CI $1.05,2 \cdot 08$ ) was positively associated with awareness of the JFG (Table 2).

From 2007 to 2009, awareness of the JFG increased in the following groups: males $(P=0 \cdot 001)$, those aged 30-39 years $(P=0 \cdot 04)$, those with a BMI of $25 \cdot 0 \mathrm{~kg} / \mathrm{m}^{2}$ or less $(P=0 \cdot 011)$, those with abdominal obesity $(P=0.036)$, the unmarried $(P=0.022)$, the married $(P=0 \cdot 032)$, less than high-school graduates $(P=0 \cdot 003)$, college graduates or more $(P=0.035)$, the employed $(P=0.004)$ and annual household income of less than 5000000 yen $(P=0 \cdot 003$; Table 3$)$.
Table 1 Basic characteristics for total respondents $(n 787)$ and general Japanese adults

\begin{tabular}{|c|c|c|c|}
\hline & \multicolumn{2}{|c|}{$\begin{array}{c}\text { Total } \\
\text { respondents }\end{array}$} & \multirow{2}{*}{$\begin{array}{c}\begin{array}{c}\text { General } \\
\text { Japaneset }\end{array} \\
\%\end{array}$} \\
\hline & $n$ & $\%$ & \\
\hline \multicolumn{4}{|l|}{ Gender } \\
\hline Female & 377 & $47 \cdot 9$ & $50 \cdot 3$ \\
\hline Male & 410 & $52 \cdot 1$ & $49 \cdot 7$ \\
\hline \multicolumn{4}{|l|}{ Age group } \\
\hline $20-29$ years & 158 & $20 \cdot 1$ & $22 \cdot 7$ \\
\hline 30-39 years & 208 & $26 \cdot 4$ & $26 \cdot 8$ \\
\hline $40-49$ years & 263 & $33 \cdot 4$ & $22 \cdot 9$ \\
\hline $50-59$ years & 158 & $20 \cdot 1$ & $27 \cdot 6$ \\
\hline \multicolumn{4}{|l|}{ BMI $\left(\mathrm{kg} / \mathrm{m}^{2}\right)$} \\
\hline$<25 \cdot 0$ & 635 & $80 \cdot 7$ & $75 \cdot 3$ \\
\hline$\geq 25 \cdot 0$ & 152 & $19 \cdot 3$ & $24 \cdot 7$ \\
\hline \multicolumn{4}{|l|}{ WC $(\mathrm{cm})$} \\
\hline Males $<85$, females $<90$ & 611 & $77 \cdot 6$ & $75 \cdot 9$ \\
\hline Males $\geq 85$, females $\geq 90$ & 176 & $22 \cdot 4$ & $24 \cdot 1$ \\
\hline \multicolumn{4}{|l|}{ Marital status } \\
\hline Unmarried & 284 & $36 \cdot 1$ & $39 \cdot 3$ \\
\hline Married & 503 & 63.9 & $60 \cdot 7$ \\
\hline \multicolumn{4}{|l|}{ Educational status } \\
\hline$\leq$ High-school graduate & 213 & $27 \cdot 1$ & $64 \cdot 0$ \\
\hline 2 years college or equivalent & 193 & $24 \cdot 5$ & $16 \cdot 3$ \\
\hline$\geq$ College graduate & 381 & $48 \cdot 4$ & $19 \cdot 6$ \\
\hline \multicolumn{4}{|l|}{ Employment status } \\
\hline Unemployment & 293 & $37 \cdot 2$ & $35 \cdot 2$ \\
\hline Employment & 494 & $62 \cdot \overline{8}$ & $64 \cdot 8$ \\
\hline \multicolumn{4}{|l|}{ Annual household income } \\
\hline$<5000000$ yen & 318 & $40 \cdot 4$ & $43 \cdot 0$ \\
\hline $5000000-9999999$ yen & 362 & $46 \cdot 0$ & $41 \cdot 5$ \\
\hline$\geq 10000000$ yen & 107 & $13 \cdot 6$ & $15 \cdot 5$ \\
\hline
\end{tabular}

WC, waist circumference.

tReference data on gender, age, marital status and employed status from the 2005 Population Census of Japan ${ }^{(18)}$; reference data on education status from the 2000 Population Census of Japan ${ }^{(19)}$; reference data on annual household income from the 2006 National Livelihood Survey ${ }^{(20)}$; reference data on BMI and WC from the National Health and Nutrition Examination Survey $2004^{(15)}$.

\section{Association between awareness of the Japanese Food Guide Spinning Top and eating behaviour score}

As shown in Table 4, the eating behaviour score of Group 2 increased significantly from 4.7 in 2007 to 5.5 in 2009 (variation $=0.8$ points; $P=0.004$ ). The eating behaviour score of Group $1(6.5$ in 2007; 6.3 in 2009; variation $=$ $-0 \cdot 2$ points) and Group $3(3 \cdot 8$ in $2007 ; 4 \cdot 1$ in 2009 ; variation $=0.3$ points) did not change significantly from 2007 to 2009 .

\section{Discussion}

Since 2006, the JFG has been disseminated to the Japanese population as a tool for promoting healthy eating by the Ministry of Agriculture, Forestry and Fisheries ${ }^{(3)}$. Thus, the present study assessed the impact of awareness of the JFG on eating behaviour among Japanese adults by using a longitudinal research design. Additionally, the study investigated the sociodemographic characteristics of Japanese adults who were not aware of the JFG. 
Table 2 Association between awareness of the Japanese Food Guide Spinning Top (JFG) in 2007 and demographic variables of respondents: Japanese adults (20-59 years) who registered with an Internet research service organization $(n 787)$

\begin{tabular}{|c|c|c|c|c|c|c|}
\hline & \multicolumn{3}{|c|}{ Unadjusted } & \multicolumn{3}{|c|}{ Adjustedt } \\
\hline & OR & $95 \% \mathrm{Cl}$ & $P$ value & OR & $95 \% \mathrm{Cl}$ & $P$ value \\
\hline \multicolumn{7}{|l|}{ Gender } \\
\hline Female & $1 \cdot 00$ & Ref. & & $1 \cdot 00$ & Ref. & \\
\hline Male & $0 \cdot 26$ & $0 \cdot 17,0.36$ & $<0 \cdot 001^{\star \star \star}$ & $0 \cdot 26$ & $0.17,0.39$ & $<0 \cdot 001^{\star * *}$ \\
\hline \multicolumn{7}{|l|}{ Age group } \\
\hline $20-29$ years & $1 \cdot 00$ & Ref. & & $1 \cdot 00$ & Ref. & \\
\hline 30-39 years & 0.99 & $0 \cdot 65,1 \cdot 50$ & 0.961 & $0 \cdot 83$ & $0.51,1 \cdot 34$ & 0.442 \\
\hline 40-49 years & $1 \cdot 03$ & $0.70,1.54$ & $0 \cdot 868$ & $0 \cdot 81$ & $0 \cdot 50,1 \cdot 31$ & 0.396 \\
\hline 50-59 years & $1 \cdot 17$ & $0 \cdot 75,1 \cdot 82$ & 0.496 & $0 \cdot 84$ & $0 \cdot 49,1 \cdot 44$ & 0.529 \\
\hline \multicolumn{7}{|l|}{ BMI $\left(\mathrm{kg} / \mathrm{m}^{2}\right)$} \\
\hline$<25 \cdot 0$ & $1 \cdot 00$ & Ref. & & $1 \cdot 00$ & Ref. & \\
\hline$\geq 25 \cdot 0$ & 0.72 & $0.50,1.02$ & 0.065 & $1 \cdot 24$ & $0.79,1.93$ & 0.347 \\
\hline \multicolumn{7}{|l|}{ WC (cm) } \\
\hline Males $<85$, females $<90$ & $1 \cdot 00$ & Ref. & & $1 \cdot 00$ & Ref. & \\
\hline Males $\geq 85$, females $\geq 90$ & 0.44 & $0.31,0.62$ & $<0 \cdot 001^{\star * *}$ & 0.65 & $0 \cdot 42,1 \cdot 00$ & $0.048^{*}$ \\
\hline \multicolumn{7}{|l|}{ Marital status } \\
\hline Unmarried & $1 \cdot 00$ & Ref. & & 1.00 & Ref. & \\
\hline Married & 1.53 & $1 \cdot 14,2 \cdot 06$ & $0 \cdot 004^{\star *}$ & $1 \cdot 37$ & $0.95,1.99$ & 0.091 \\
\hline \multicolumn{7}{|l|}{ Educational status } \\
\hline$\leq$ High-school graduate & $1 \cdot 00$ & Ref. & & 1.00 & Ref. & \\
\hline 2 years college or equivalent & $1 \cdot 48$ & $0.98,2 \cdot 21$ & 0.060 & $1 \cdot 07$ & $0 \cdot 69,1 \cdot 65$ & $0 \cdot 772$ \\
\hline$\geq$ College graduate & $0 \cdot 72$ & $0.51,1 \cdot 01$ & 0.057 & $0 \cdot 88$ & $0 \cdot 61,1 \cdot 29$ & 0.516 \\
\hline \multicolumn{7}{|l|}{ Employment status } \\
\hline Unemployment & $1 \cdot 00$ & Ref. & & 1.00 & Ref. & \\
\hline Employment & 0.54 & $0 \cdot 40,0 \cdot 72$ & $<0 \cdot 001^{\star * *}$ & $1 \cdot 40$ & $0 \cdot 93,2 \cdot 01$ & $0 \cdot 111$ \\
\hline \multicolumn{7}{|l|}{ Annual household income } \\
\hline$<5000000$ yen & $1 \cdot 00$ & Ref. & & 1.00 & Ref. & \\
\hline $5000000-9999999$ yen & $1 \cdot 53$ & $1 \cdot 13,2 \cdot 07$ & $0 \cdot 007^{\star \star}$ & $1 \cdot 48$ & $1 \cdot 05,2 \cdot 08$ & $0.024^{\star}$ \\
\hline$\geq 10000000$ yen & $1 \cdot 10$ & $0 \cdot 71,1 \cdot 70$ & 0.677 & $1 \cdot 19$ & $0.73,1.97$ & 0.485 \\
\hline
\end{tabular}

WC, waist circumference; Ref., referent category.

${ }^{*} P<0.05 ;{ }^{* *} P<0.01 ;{ }^{* * *} P<0.001$.

tAdjusted for gender, age group, BMI, WC, marital status, educational status, employment status and annual household income.

Regarding the dissemination of the JFG from 2007 to 2009, there was a positive relationship between awareness of the JFG and eating behaviour. The present study found that $61 \cdot 8 \%$ of Japanese adults were aware of the JFG in 2009, and Japanese adults who newly become aware of the JFG by 2009 engaged in healthier eating in 2009 compared with those who were not aware of the JFG by 2009. These findings suggest that a nationwide campaign for promoting the JFG would lead not only to large increases in awareness levels but also to significant positive changes in eating behaviour towards healthier eating habits among Japanese adults. In the process of behavioural change, awareness of key health messages is an important and initial step ${ }^{(21)}$. The promotion of the JFG may be an effective strategy to establish healthy eating patterns in the Japanese population. Previous studies $^{(9,10)}$ observed the positive association between awareness of the message or campaign and behaviour using a cross-sectional research design. The results of the present study using a longitudinal design replicated and clearly strengthened the findings of previous studies, and provided findings regarding the positive impact of awareness of nutrition messages such as the JFG on eating behaviour in a nationwide campaign. The unique part of the JFG is that it is expressed in quantities of the 'dish' rather than in the 'food' format to estimate the quantity of food consumed in a daily diet, and it is expressed using the analogy of a spinning top ${ }^{(2)}$. When specifying the amount of food intake, the following three viewpoints can be considered: (i) nutrition-based; (ii) food-based; and (iii) dish-based ${ }^{(1)}$. The dish-based format is easy to understand for not only those who prepare meals but also those who eat them ${ }^{(2)}$. The visual message of the JFG, from which perhaps people can easily understand 'what' and 'how much' they should eat, might cause behavioural changes in awareness of the JFG.

Awareness of the JFG increased significantly during the nationwide campaign; $61 \cdot 8 \%$ of respondents were aware of the JFG in 2009, three years after the nationwide campaign launched $(56.0 \%$ in 2007). The high levels of JFG awareness were comparable to those found in previous studies $^{(8,10)}$. For example, spontaneous awareness of the 'Go for $2 \& 5^{\circledR}$, campaign in Western Australia was $62.4 \%$ in 2004 after three years of the intervention ${ }^{(10)}$. The present study noted that JFG awareness was significantly lower in males, those with abdominal obesity, the unmarried and employed respondents in 2007 (JFG awareness: $56 \%$ ), and male gender and abdominal obesity were negatively associated with awareness of the JFG after adjustment. According to a previous study of the 
Table 3 Change in awareness of the Japanese Food Guide Spinning Top (JFG) from 2007 to 2009 according to demographic variables of respondents: Japanese adults (20-59 years) who registered with an Internet research service organization ( $n$ 787)

\begin{tabular}{|c|c|c|c|}
\hline & \multicolumn{2}{|c|}{$\begin{array}{c}\text { Awareness of the } \\
\text { JFG (\%) }\end{array}$} & \multirow[b]{2}{*}{$P$ valuet } \\
\hline & 2007 & 2009 & \\
\hline Total & $56 \cdot 0$ & $61 \cdot 8$ & $0.001^{\star *}$ \\
\hline \multicolumn{4}{|l|}{ Gender } \\
\hline Female & $72 \cdot 4$ & $74 \cdot 8$ & $0 \cdot 356$ \\
\hline Male & $41 \cdot 0$ & $49 \cdot 8$ & $0 \cdot 001^{\star *}$ \\
\hline \multicolumn{4}{|l|}{ Age group } \\
\hline $20-29$ years & $55 \cdot 1$ & $62 \cdot 0$ & $0 \cdot 126$ \\
\hline 30-39 years & $54 \cdot 8$ & $62 \cdot 0$ & $0 \cdot 04^{*}$ \\
\hline $40-49$ years & $55 \cdot 9$ & $60 \cdot 5$ & $0 \cdot 162$ \\
\hline 50-59 years & $58 \cdot 9$ & $63 \cdot 3$ & $0 \cdot 349$ \\
\hline \multicolumn{4}{|l|}{ BMI $\left(\mathrm{kg} / \mathrm{m}^{2}\right)$} \\
\hline$<25 \cdot 0$ & $57 \cdot 6$ & $62 \cdot 8$ & $0 \cdot 011^{*}$ \\
\hline$\geq 25 \cdot 0$ & $49 \cdot 3$ & $57 \cdot 2$ & 0.050 \\
\hline \multicolumn{4}{|l|}{ WC (cm) } \\
\hline Males $<85$, females $<90$ & $60 \cdot 6$ & $65 \cdot 5$ & $0 \cdot 017^{\star}$ \\
\hline Males $\geq 85$, females $\geq 90$ & $40 \cdot 3$ & $48 \cdot 9$ & $0.036^{*}$ \\
\hline \multicolumn{4}{|l|}{ Marital status } \\
\hline Unmarried & $49 \cdot 3$ & $56 \cdot 7$ & $0.022^{*}$ \\
\hline Married & $59 \cdot 8$ & $64 \cdot 6$ & $0.032^{*}$ \\
\hline \multicolumn{4}{|l|}{ Educational status } \\
\hline$\leq$ High-school graduate & $57 \cdot 7$ & $67 \cdot 6$ & $0.003^{\star *}$ \\
\hline 2 years college or equivalent & $66 \cdot 8$ & $67 \cdot 4$ & $1 \cdot 000$ \\
\hline$\geq$ College graduate & $49 \cdot 6$ & $55 \cdot 6$ & $0.035^{*}$ \\
\hline \multicolumn{4}{|l|}{ Employment status } \\
\hline Unemployment & $65 \cdot 5$ & $69 \cdot 6$ & $0 \cdot 182$ \\
\hline Employment & $50 \cdot 4$ & $57 \cdot 1$ & $0 \cdot 004^{\star *}$ \\
\hline \multicolumn{4}{|l|}{ Annual household income } \\
\hline$<5000000$ yen & $50 \cdot 9$ & $59 \cdot 1$ & $0.003^{\star *}$ \\
\hline $5000000-9999999$ yen & $61 \cdot 3$ & $65 \cdot 5$ & $0 \cdot 128$ \\
\hline$\geq 10000000$ yen & $53 \cdot 3$ & $57 \cdot 0$ & $0 \cdot 608$ \\
\hline
\end{tabular}

WC, waist circumference

${ }^{*} P<0.05 ;{ }^{* *} P<0.01 ;{ }^{* * *} P<0.001$

tMcNemar test.

Victorian ' 2 Fruit 'n' 5 Veg Every Day' campaign, awareness of the campaign slogan was $70 \%$ after one year of promotion and was lower in males, those with more education and households classified as 'white collar'(8). Obesity is known as a risk factor for CVD, type 2 diabetes and other chronic conditions ${ }^{(22)}$. In particular, abdominal obesity is currently considered as a core component of metabolic syndrome ${ }^{(23)}$. In Japan, the proportion of obese individuals has increased among males aged 20-69 years ${ }^{(24)}$. Thus, male gender and abdominal obesity are the target subgroups for dissemination of the JFG in Japan. The results of the present study showed that the awareness level of the JFG has increased significantly among males and abdominal obesity three years after the nationwide campaign launched, indicating that the JFG is disseminated effectively throughout the nation based on the programme by the Ministry of Agriculture, Forestry and Fisheries.

JFG awareness was positively related to healthy eating behaviour. According to a previous study examining the association between utilization of health information sources (i.e. mass media and interpersonal) and healthy

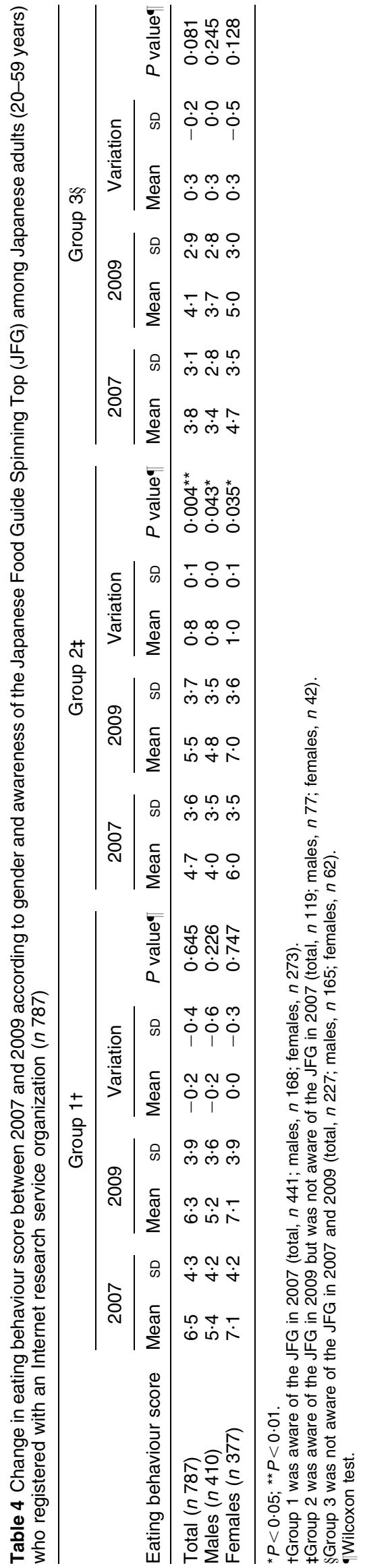


behaviours, some health behaviours improved as the number of health information sources increased ${ }^{(25)}$. That is, perhaps the Japanese people with healthier eating were likely to be aware of the health information such as the JFG in nationwide campaigns. Meanwhile, those with unhealthier eating were less likely to be aware of the JFG, thus it is necessary to develop additional campaign strategies for specifically reaching those with unhealthier eating or little interest in improving their diets.

The present investigation had two limitations. The first is that weight, height and WC were assessed using self-reported values, which could have been unreliable and inconsistent. Second, the study was conducted in an Internet setting. The Internet-based surveys used monitor registration - a purposive sampling method - and thus are associated with sampling errors. Rhodes et $a l^{(26)}$ mentioned that individuals who are younger, more educated and have a higher income have greater access to the Internet. Therefore, the basic characteristics of the respondents might be biased, implying that the findings under such a setting might not be sufficiently applicable to the general population.

\section{Conclusions}

Awareness of the JFG promoted eating behaviour change in the Japanese population. The results indicate that the awareness of nutritional information by sources such as the JFG could promote healthy eating among Japanese adults. In addition, the dissemination of the JFG by the nationwide campaign was successful in reaching the target population groups, which were male and abdominal obesity, promoting awareness of the JFG and encouraging them to engage in healthy eating behaviour.

\section{Acknowledgements}

This work was supported by the Waseda University Grant for Special Research Projects (Project number: 2007B-235) and a Grant-in-Aid for Scientific Research (21-57091). The work was conducted as part of the Global COE Program Sport Sciences for the Promotion of Active Life - at Waseda University. The authors declare that they have no competing interest. K.T. participated in the design of the study, performed the statistical analysis and drafted the manuscript. Y.N. conceived the study, participated in its design and coordination, and helped in drafting the manuscript. K.H. participated in the design of the study and helped in data processing. A.S. helped in drafting the manuscript. All the authors have read and approved the final manuscript. The authors would like to extend their appreciation to the respondents. They are grateful for all assistance received from staff and students during the study.

\section{References}

1. Food Guide Study Group, Ministry of Health, Labour and Welfare \& Ministry of Agriculture, Forestry and Fisheries (2005) Report of the Food Guide Study Group: Food Guide Spinning Top. http://www.j-balanceguide.com/pdf/guide_ exam1.pdf (accessed July 2010).

2. Yoshiike N, Hayashi F, Takemi Y et al. (2007) A new food guide in Japan: the Japanese Food Guide Spinning Top. Nutr Rev 65, 149-154.

3. Takaizumi K \& Nakamura Y (2010) Dissemination strategy of the Japanese Food Guide Spinning Top by the Ministry of Agriculture, Forestry and Fisheries. JJpn Soc Sports Ind 20, 139-142.

4. Snyder LB (2007) Health communication campaigns and their impact on behavior. J Nutr Educ Behav 39, 2 Suppl., S32-S40.

5. Cavill N \& Bauman A (2004) Changing the way people think about health-enhancing physical activity: do mass media campaigns have a role? J Sports Sci 22, 771-790.

6. McGuire WJ (1984) Public communication as a strategy for inducing health promoting behavioral change. Prev Med 13, 299-319.

7. Takaizumi K, Harada K, Shibata A et al. (2011) Influence of awareness of the Japanese Food Guide Spinning Top on eating behavior and obesity. Asia Pac J Clin Nutr 20, 95-101.

8. Dixon H, Borland R, Segan C et al. (1998) Public reaction to Victoria's '2 Fruit ' $n$ ' 5 Veg Every Day' campaign and reported consumption of fruit and vegetables. Prev Med 27, 572-582.

9. Eckel RH, Kris-Etherton P, Lichtenstein AH et al. (2009) Americans' awareness, knowledge, and behaviors regarding fats: 2006-2007. J Am Diet Assoc 109, 288-296.

10. Pollard CM, Miller MR, Daly AM et al. (2008) Increasing fruit and vegetable consumption: success of the Western Australian Go for $2 \& 5$ campaign. Public Health Nutr 11, 314-320.

11. Sun X, Guo Y, Wang S et al. (2007) Social marketing improved the consumption of iron-fortified soy sauce among women in China. J Nutr Educ Behav 39, 302-310.

12. Wellings K \& Macdowall W (2000) Evaluating mass media approaches to health promotion: a review of methods. Health Educ 100, 23-32.

13. Ministry of Internal Affairs and Communications (2008) Information \& Communications Statistics Database. http:// www.soumu.go.jp/johotsusintokei/english/ (accessed June 2011).

14. Japan Health Promotion \& Fitness Foundation (2000) Health Japan 21. http://www.kenkounippon21.gr.jp/ (accessed July 2010).

15. Ministry of Health, Labour and Welfare (2004) National Health and Nutrition Examination Survey 2004. http:// www.mhlw.go.jp/bunya/kenkou/eiyou06/01.html (accessed July 2010).

16. Inoue M, Toyokawa S, Miyoshi Y et al. (2007) Degree of agreement between weight perception and body mass index of Japanese workers: MY Health Up Study. J Occup Health 49, 376-381.

17. The Examination Committee of Criteria for 'Metabolic Syndrome' in Japan (2005) The definition and criteria of metabolic syndrome. Nibon Naika Gakkai Zasshi 94, 794-809.

18. Japan Statistical Association (2007) 2005 Population Census of Japan. Tokyo: Japan Statistical Association, Statistics Bureau Ministry of Public Management, Home Affairs, Post and Telecommunications.

19. Japan Statistical Association (2001) 2000 Population Census of Japan. Tokyo: Japan Statistical Association, Statistics Bureau Ministry of Public Management, Home Affairs, Post and Telecommunications. 
20. Ministry of Health, Labour and Welfare (2006) Summary of National Livelihood Survey 2006. http://www.mhlw.go.jp/ toukei/saikin/hw/k-tyosa/k-tyosa06/index.html （accessed July 2010).

21. Prochaska JO, DiClemente CC \& Norcross JC (1992) In search of how people change: applications to addictive behaviors. Am Psychol 47, 1102-1114

22. National Institutes of Health (1998) Clinical guidelines on the identification, evaluation and treatment of overweight and obesity in adults: the evidence report. http://www.nhlbi.nih.gov/guidelines/obesity/ob_gdlns.pdf (accessed July 2010).
23. Alberti KG, Zimmet P \& Shaw J (2005) The metabolic syndrome - a new worldwide definition. Lancet 366, 1059-1062.

24. Udagawa K, Miyoshi M \& Yoshiike N (2008) Mid-term evaluation of 'Health Japan 21': focus area for the nutrition and diet. Asia Pac J Clin Nutr 17, 445-452.

25. Redmond N, Baer HJ, Clark CR et al. (2010) Sources of health information related to preventive health behaviors in a national study. Am J Prev Med 38, 620-627.

26. Rhodes SD, Bowie DA \& Hergenrather KC (2003) Collecting behavioural data using the world wide web: considerations for researchers. J Epidemiol Community Health 57, 68-73.

\section{Appendix}

\section{Question items on eating behaviour}

\section{Question item}

1. Are you abstaining from fatty food?

2. Are you abstaining from salty food?

3. Are you eating a lot of vegetables?

4. Do you eat breakfast?

5. Do you check nutrient labels when eating out or purchasing foods?

6. Do you take your time while eating?

7. Do you only eat as much as you need?

8. Are you eating well-balanced meals?

9. Are you eating a combination of grain dishes (rice, bread, noodles), fish and meat dishes (meat, fish, eggs, soyabean) and vegetable dishes?

10. Are you eating an appropriate amount of milk and milk products?

11. Are you eating an appropriate amount of fruit?

12. Do you enjoy eating appropriate amounts of snacks and soft drinks?

13. Do you enjoy drinking an appropriate amount of alcohol?

14. Are you eating your required amount of calories?

15. Are you trying to reach or maintain your ideal weight?

16. Are you trying to eat the best meals as possible?

Questions 1-5 and 16 relate to the eating behaviour recommended by Health Japan 21 (Japan Health Promotion \& Fitness Foundation, $2000^{(15)}$ ).

Questions 8-14 relate to the eating behaviour recommended by The Japanese Food Guide Spinning Top (Food Guide Study Group, $\left.2005^{(1)}\right)$.

Questions 6, 7 and 15 are those used in the National Health and Nutrition Examination Survey 2004 (Ministry of Health, Labour and Welfare, $2007^{(16)}$ ). 